\title{
Fabrication of Gastro-retentive Controlled Drug Delivery Systems Based on N-isopropylacrylamide Hydrogels
}

\author{
Rubab Zohra ${ }^{1 *}$ and Muhammad Aslam Malana ${ }^{2}$ \\ ${ }^{1}$ Department of Chemistry, Forman Christian College, Pakistan \\ ${ }^{2}$ Department of Chemistry, Bahauddin Zakarya University, Pakistan
}

Submission: January 11, 2018; Published: April 10, 2018

"Corresponding author: Rubab Zohra, Professor, Department of Chemistry, Forman Christian College, Lahore, Pakistan, Tel: 0092-03346881524; Email: rubabzohra@gmail.com

\begin{abstract}
The research work was planned to fabricate $\mathrm{N}$-isopropylacrylamide based hydrogels to incorporate dual-sensitivity to control the drug delivery in the post intestinal tract. The necessary mechanical strength was attained introducing methacrylate (MA) whereas the swelling control was achieved using acrylic acid (AA) as a hydrophilic component. Using Benzoylperoxide (BPO) as an initiator and Ethylalcohol as a solvent, the polymerization was carried out through free radical method. Diethylene glycol dimethacrylate (DEGDMA) and ethylene glycol dimethacrylate (EGDMA) worked as chemical cross linking agents. Applying the Flory-Rehnerequation, the network parameters such as mesh size ( $\xi$ ), molecular weight between the cross-links (Mc) and crosslink density (q) were determined under various pH and temperature conditions. The swelling mechanism was found to be the non-Fickian, for most of the hydrogel systems. The characterization of the synthesized hydrogels was carried out using FTIR (Fourier Transform Infrared) spectres copy and TGA/DSC (Thermogravimetric Analysis/Differential Scanning Calorimetery). The LCST (lower critical solution temperature) was found to be increased by 2oC. Tramadol HCl was loaded in specific concentration and its release mechanism and order was investigated applying different models. Ultimately, it was observed that these systems have a great potential to be used as controlled drug delivery system in the alkaline $\mathrm{pH}$ of the post intestinal tract.
\end{abstract}

Keywords: Controlled; Drug delivery; Hydrogels; N-isopropylacrylamide; Fabrication

\section{Introduction}

The recent research reveals that most of the systems available for the post intestinal tract get their efficiency reduced by the acidic medium of gastric tract especially by proteolytes of the stomach and absorption in initial part of small intestine. The sensitivity of hydrogels towards various stimuli such as $\mathrm{pH}$, temperature etc. has provided a way to overcome the problems while targeting colon part of gastro intestinal tract [1-3]. But the drug release mechanism of the fabricated system still requires attention of researchers [4,5]. The LCST (32 oC) of Poly ( $\mathrm{N}$-isopropylacrylamide) (PNiPAAm) based hydrogels is very close to the human body temperature (32 oC), so have a considerable weight age regarding controlled drug delivery system [6,7]. In fact, the LCST of these gels is considered to be tuned by adjusting the hydrophobic and hydrophilic ratio in the gel systems to get the required therapeutic effect of the drug administered.

\section{Experimental Section}

The controlled drug delivery systems was fabricated using $\mathrm{N}$-isopropylacrylamide (NiPAAm), acrylic acid (AA) and methacrylate (MA) as monomers, chemically cross-linked with EGDMA and DEGDMA. To avoid any interference by the dissolved oxygen, nitrogen gas was bubbled through all the reaction mixtures. The free radical polymerization process was carried out using various buffers and temperatures keeping in a thermostat. Details of heating scheme have been published [8]. After characterization, the hydrogel samples were loaded with Tramadol $\mathrm{HCl}$ to be used as a sample drug and the mechanism was studied in detail. Following equations and models were applied for study of swelling behavior, drug loading and drug release mechanisms of the fabricated hydrogels:

Swelling percentage $\mathrm{S} \%=\mathrm{m}_{\mathrm{t}}-\mathrm{m}_{\mathrm{o}} / \mathrm{m}_{\mathrm{o}} \times 100$

Fick's model $\ln \left(\mathrm{W}_{\mathrm{t}} / \mathrm{W}_{\mathrm{e}}\right)=\ln \mathrm{k}+\mathrm{n} \ln \mathrm{t}$ 
Schott's model $\mathrm{t} / \mathrm{W}=1 / \mathrm{k}_{\mathrm{s}} \mathrm{W}_{\mathrm{e}}{ }^{2}+1 / \mathrm{W}_{\mathrm{e}} \mathrm{t}$

Absorbency $(\mathrm{Q})=\left(\mathrm{C}_{1} \mathrm{~V}_{1}-\mathrm{C}_{2} \mathrm{~V}_{2}\right) / \mathrm{m}_{\mathrm{o}}$

Zero order equation $Q_{t}=k_{0} \cdot t$

First order equation $\ln \left(100-\mathrm{Q}_{\mathrm{t}}\right)=\ln 100-\mathrm{k}_{1} \mathrm{t}$

Higuchi's equation $Q_{\mathrm{t}}=\mathrm{k}_{\mathrm{H}} \cdot \mathrm{t}^{1 / 2}$

Hixson-Crowell model $(100-\mathrm{Qt})^{1 / 3}=100^{1 / 3}-\mathrm{k}_{\mathrm{HC}} \cdot \mathrm{t}$

$\mathrm{Q}_{\mathrm{t}} / \mathrm{Q}_{\mathrm{e}}=\mathrm{k}_{\mathrm{KP}} \cdot \mathrm{t}^{\mathrm{n}}$

Results and Discussion

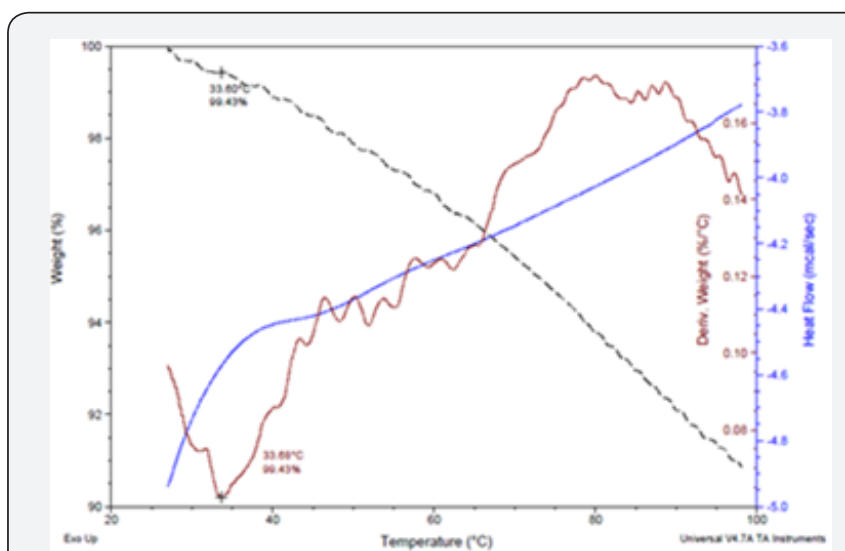

Figure 1: Representative DSC/TGA diagram indicating the increase in LCST of NiPAAm hudrogels.

Thy hydrogels were prepared using slow heating rates. The characteristic peaks obtained in FTIR spectrums indicated the successful synthesis of hydrogel systems. Thermal studies carried out by DSC/TGA revealed the shifting of LCST of the fabricated hydrogels by 2 oC. The morphological analysis by Scanning electron microscopy pointed out the presence of a variety of pores on the surface of the hydrogel disks, owing to the incorporation of many monomers while fabricating the hydrogels. During swelling studies, it was observed that the gels underwent a favorable swelling in basic media and prevented from the drug release in the acidic pH of solution (Figure 1). It was considered that the acrylic acid content was having pendant carboxylic groups which were responsible not only for increasing the swelling process by controlling the network parameters but also controlling the drug release behavior of gels. Network parameters like polymer mesh size ( $\xi$ ) (23.78 to $820 \AA$ ), molecular weight between the cross-links (Mc) (970356096 gmol-1) and crosslink density (q), (0.0928 to 0.00025) calculated at various $\mathrm{pH}$ using the Flory-Rehner Theoryalso strengthened the deduction that basic medium is supporting the process of swelling. The drug was loaded in vitro to prevent from any interaction of the reaction mixture with the active agent if it is loaded in situ. The drug release studies revealed that the initial concentration of the drug in the loading solution and the concentration of AA in the gel network structure are highly effective for controlling the release mechanism (Figure 2). This is, perhaps, due to the concentration gradient developed between the drug system and the release medium and the osmotic pressure developed by the hydrophilic component respectively (Figure 3).

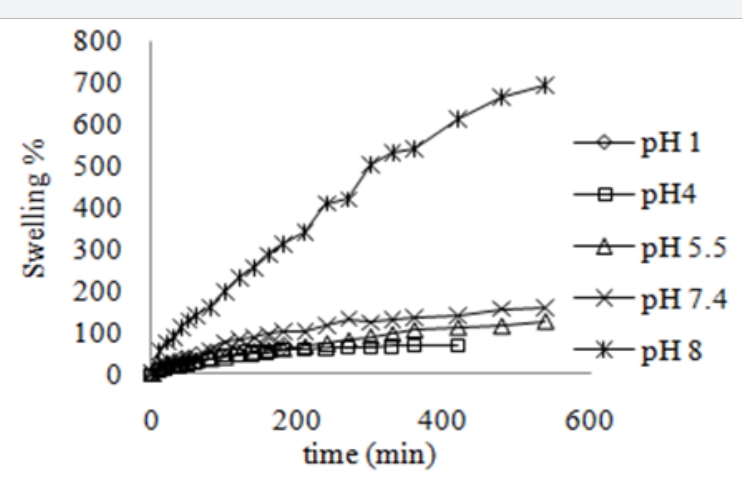

Figure 2: Effect of $\mathrm{pH}$ on swelling percentage and equilibrium swelling of the poly (MA-co-NiPAAm-co-AA) cross-linked with DEGDMA.

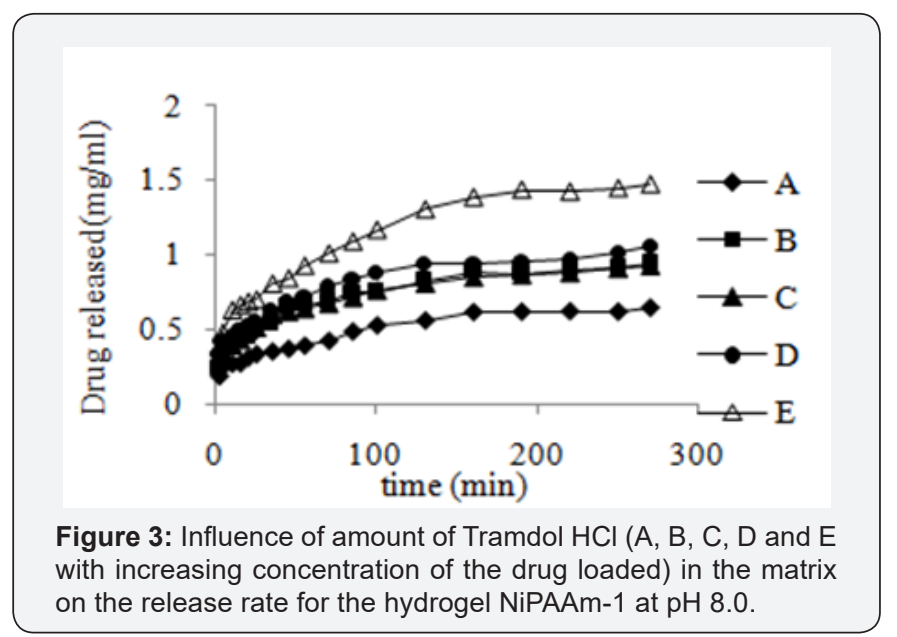

\section{Conclusion}

It is concluded that the fabricated hydrogels can be tuned by adjusting the hydrophilic and hydrophobic ratio in the gel structure. The increased value of LCST supports the idea that the hydrophilic component has a great influence for controlling its behavior according to the application. The hydrogels resisted against the acidic medium so may be proved successful to accommodate the acidic $\mathrm{pH}$ of the stomach. The disks maintained their shapes in acidic medium so it can be supposed to offer resistance against the peristaltic movements of the stomach because of having necessary mechanical strength owing to the hydrophobic component and the chemical cross linking agent used during their synthesis.

\section{References}

1. Jeong B, Kim SW, Bae YH (2002) Thermosensitive sol-gel reversible hydrogels. Adv Drug Deliver Rev 54(1): 37-51.

2. Chen GH, Hoffman AS (1995) Graft co-polymers that exhibit temperature-induced phase transitions over a wide range of $\mathrm{pH}$. Nature 373(6509): 49-52. 
3. Malana MA, Zohra R (2013) The release behavior and kinetic evaluation of tramadol $\mathrm{HCl}$ from chemically cross linked co-polymeric hydrogels. DARU J Pharm Sci 21(1): 1-10.

4. Pham AT, Lee PI (1994) Probing the mechanism of drug release from hydroxyl propyl methy cellulose (hpmc) matrices. Pharm Res 11(10): 1379-1384.

5. Colombo P, Bettini R, Massimo G, Catellani PL, Santi P, et al. (1995) Drug diffusion front movement is important in drug release control from swellable matrix tablets. J Pham Sci 84(8): 991-997.

6. Han H, Shin BC, Choi HS (2008) Doxorubicin-encapsulated thermo- sensitive liposomes modified with poly (n-isopropyleacrylamide-coacrylamide): Drug release behavior and stability in the presence of serum. Eur J Pharm Biopharm 62(1): 110-116.

7. Akdemir Z, Kayaman AN (2007) Investigation of swelling, drug release and diffusion behaviors of poly (n-isopropylacrylamide)/poly (n-vinylpyrrolidone) full-IPN hydrogels. Polym Adv Technol 18(11): 932-939.

8. Dimitrov M, Lambov N, Shenkov S, Dosseva V, Baranovski VY (2003) Hydrogels based on chemically cross linked polyacrylic acid: biopharmaceutical chacterization. Acta Pharm 53(1): 25-31.

\section{Your next submission with JuniperPublishers will reach you the below assets}

- Quality Editorial service

- Swift Peer Review

- Reprints availability

- E-prints Service

- Manuscript Podcast for convenient understanding

- Global attainment for your research

- Manuscript accessibility in different formats ( Pdf, E-pub, Full Text, audio)

- Unceasing customer service

Track the below URL for one-step submission https://juniperpublishers.com/online-submission.php 